\title{
Development and Characterization of Microsatellite Markers for a Little Bluestem Collection
}

\author{
Karen Harris-Shultz ${ }^{1}$ \\ USDA-ARS, Crop Genetics and Breeding Research Unit, 115 Coastal Way, Tifton, GA 31793 \\ Melanie Harrison \\ USDA-ARS, Plant Genetic Resources and Conservation Unit, 1109 Experiment Street, Griffin, GA \\ 30223 \\ Phillip A. Wadl and Robert N. Trigiano \\ University of Tennessee, Department of Entomology and Plant Pathology, 2431 Joe Johnson Drive, \\ 205 Ellington Plant Science Building, Knoxville, TN 37996 \\ Timothy Rinehart \\ USDA-ARS, Southern Horticultural Laboratory, 810 Highway 26 West, Poplarville, MS 39470
}

AdDitional INDEX words. Schizachyrium scoparium, ornamental grass, SSR marker, population structure, ploidy

\begin{abstract}
Little bluestem (Schizachyrium scoparium) is a perennial bunchgrass that is native to North American prairies and woodlands from southern Canada to northern Mexico. Originally used as a forage grass, little bluestem is now listed as a major U.S. native, ornamental grass. With the widespread planting of only a few cultivars, we aimed to assess the ploidy level and genetic diversity among some popular cultivars and accessions in the U.S. Department of Agriculture National Plant Germplasm System collection. Ten microsatellite markers, with successful amplification, were developed by using sequences available in Genbank and additional simple sequence repeat (SSR) markers were generated by using ion torrent sequencing of a genomic library created from the cultivar The Blues. A total of 2812 primer sets was designed from high-throughput sequencing, 100 primer pairs were selected, and 82 of these primers successfully amplified DNA from the Schizachyrium accessions. Only 35 primer pairs, generating 102 scored fragments, were polymorphic among $S$. scoparium accessions. Twenty-two primer pairs generated more than four fragments per accession. The use of a repetitive sequence identifier found that of 117 examined sequences, only nine sequences did not have similarity to DNA transposons, retrotransposons, viruses, or satellite sequences. The most frequently identified fragments were the long terminal repeat retrotransposons Gypsy (177 fragments) and Copia (98 fragments) and the DNA transposon EnSpm (60 fragments). Using the software program Structure, cluster analysis of the SSR data for $S$. scoparium revealed four groups. The lowest genetic similarity between little bluestem samples was $86 \%$, which was surprising as a high degree of morphological variation is seen in this species. Furthermore, no variation in ploidy level was seen among little bluestem samples. These microsatellite markers are the first sequence-specific markers designed for little bluestem and can serve as a resource for future genetic studies.
\end{abstract}

Ornamental grasses have become exceedingly popular in the United States as a result of gardeners' acceptance of a more natural landscape appearance and the low maintenance requirements of ornamental grasses (Meyer, 2012). Sales of ornamental grasses in the United States were $\approx \$ 124$ million in 2009 [U.S. Department of Agriculture (USDA), 2012], up from \$61 million in 2003 (Meyer, 2012). With the priority of many federal, state, and local governments to plant native grasses on public land and governmental requirements for native grasses to be planted at sites for oil exploration, pipeline, and mine-site reclamation (Smith and Whalley, 2002), and the acceptance by gardeners of ornamental grasses, sales are increasing in the United States. The ornamental grass little bluestem is now listed as a major U.S. native ornamental grass (Meyer, 2012).

Received for publication 16 Sept. 2014. Accepted for publication 5 Dec. 2014. We gratefully thank Hongliang Wang, David Sack, and Kelcie Barnes for their technical help and Dr. Joseph Knoll for his comments regarding the manuscript. Mention of trade names or commercial products in this publication is solely for the purpose of providing specific information and does not imply recommendation or endorsement by the U.S. Department of Agriculture.

${ }^{1}$ Corresponding author. E-mail: Karen.Harris@ars.usda.gov.
Little bluestem [ $2 n=4 x=40$ (Carman and Hatch, 1982)], a segmental allotetraploid (Deward and Jalal, 1974) formerly known as Andropogon scoparius, is a warm-season perennial bunchgrass found throughout North America (except Nevada and Oregon), southern Canada, and Mexico. Little bluestem is a mycorrhizal plant, associating with Glomus sp. (Anderson et al., 1984), that has a phosphorus requirement that is extremely low (Wuenscher and Gerloff, 1971). Little bluestem is drought-tolerant, displays facultative self-pollination, is morphologically plastic (Fernald, 1950), and forms silvery blue clumps 0.3 to $0.6 \mathrm{~m}$ in height. Furthermore, it can show wide variability in height and form. Flowering spikelets are produced in late summer through fall and range in color from blue-green to silvery gold. The uses of little bluestem have been for forage, hay production, range and conservation plantings, erosion control, as a potential lignocellulose biomass feedstock (Gonzalez-Hernandez et al., 2009), and native ornamental grass. No serious insect or disease problems have been reported.

In the past, seeded cultivars of little bluestem were developed for use in pastures and for conservation and include the cultivars Aldous, Badlands Ecotype, Cimmaron, Pastura, Prairie View, and Southlow Michigan. New horticultural marketing 
programs such as Proven Winners (Meyer, 2012) and web sites promoting native plants have successfully targeted consumers to buy ornamental grasses.

Few genetic or genomic tools are available for little bluestem, although non-sequence-specific random amplified polymorphic DNA [RAPD (Huff et al., 1998)] and amplified fragment length polymorphisms (AFLP) markers (Fu et al., 2004) have been used to assess genetic diversity. Fu et al. (2004) assessed the genetic diversity of six natural populations of little bluestem in Manitoba and Saskatchewan and Huff et al. (1998) assessed genetic variation within and among four populations from New Jersey and Oklahoma. Both studies found that a high proportion of the genetic variability was found within the populations and only a small percentage was represented among populations (Fu et al., 2004; Huff et al., 1998). The authors conclude that the patterns of molecular variation demonstrated by AFLP and RAPD are not associated with geographical origins of the populations. Thus, the genetic variation observed in AFLP and RAPD studies within populations and between individuals may be the result of outcrossing and gene flow through pollen and seed dispersal.

Morphological variation, although easily observed within populations, is not a useful indicator of provenance, habitat, or genetic divergence. From a conservation standpoint, substantial genetic variation could be captured by sampling relatively few individuals from single sites because genetic divergence among natural populations is weak when analyzed with geographic distance (Fu et al., 2004). It is worth noting that the slight but significant differences, observed among populations by Fu et al. (2004) and Huff et al. (1998), are relatively small compared with other outcrossing species (Hamrick and Godt, 1989).

Simple sequence repeat markers, or microsatellites, are repeating DNA sequences of one to six nucleotides that are found in coding and non-coding regions of the genome (Toth et al., 2000). SSR markers, including expressed sequence tag markers, have a wide range of uses such as linkage map development, quantitative trait locus mapping, marker-assisted selection, parentage analysis, cultivar fingerprinting, and genetic diversity studies (Egan et al., 2012). Traditionally SSR development has been completed by creating enriched genomic libraries, mining from databases, and the transfer of SSR markers from closely related species. The use of next-generation sequencing platforms generates thousands of SSRs efficiently and cost-effectively and has been successfully used in warmseason grasses (Harris-Shultz et al., 2013; Mulkey et al., 2013). With the interest in little bluestem, and the horticultural planting of a few recommended cultivars, we aimed to determine ploidy level and to create SSR markers to assess the genetic diversity among the USDA-Agricultural Research Service (ARS) National Plant Germplasm System (NPGS) collection.

\section{Material and Methods}

Plant material. Seeds from two accessions of $S$. condensatum, two accessions of $S$. sanguineum, and 75 accessions of $S$. scoparium were obtained from the USDA-ARS NPGS (Table 1) (USDA, 2013). One seed per accession randomly selected, except for four accessions, was potted in commercial potting medium (Metro-Mix 360; Sun Gro Horticulture, Agawam, MA). The seeded cultivars PI 421552 [Cimmarron (10 individual plants)], PI 421553 [Aldous (10 individual plants)], PI 642388 [Prairie View (nine individual plants)], and PI 648369 [Pastura (nine individual plants)] were obtained from the USDA-ARS NPGS and used to examine diversity within plants of the same accession.

LIBRARY CONSTRUCTION, ION TORRENT SEQUENCING, AND MICROSATELLITE DISCOVERY. DNA was extracted from the little bluestem cultivar The Blues using a Power Plant Pro DNA Isolation kit (MO Bio Laboratories, Carlsbad, CA). 'The Blues' was provided by M. Harrison. A genomic DNA library (400 bp read) was developed for 'The Blues' by following the manufacturer's instructions using the Ion Xpress Plus gDNA Fragment Library Preparation kit (Life Technologies, Carlsbad, CA). After fragment preparation and prior sequencing, the library was quantified using the Ion Library Quantitation Kit (Life Technologies) to determine the appropriate library dilution. After library dilution, the library was enriched with Ion Sphere Particles using the Ion personal genome machine (PGM) Template OT2 400 Kit (Life Technologies) in preparation for sequencing. The library was sequenced on the Ion PGM System (Life Technologies) using the Ion PGM Sequencing $400 \mathrm{Kit}$ (Life Technologies) and Ion 318 Chip v2 (Life Technologies). The sequencing reads were assembled into contigs using the default parameters in SeqMan NGen software (DNASTAR, Madison, WI). Contigs were exported in FASTA format for microsatellite discovery. The sequences were searched for microsatellites (di- to hexa-nucleotide motifs) and primers were designed using BatchPrimer3 (You et al., 2008). Primer design used the default settings except that minimum, optimal, and maximum primer melting temperatures were set to $55.0,60.0$, and $65.0^{\circ} \mathrm{C}$, respectively. The software program Censor was used to identify those contigs with repetitive elements (Kohany et al., 2006).

DNA EXTRaCtion AND PCR AMPlification OF SSRs from THE GERMPLASM COLLECTION. DNA was extracted from 78 Schizachyrium accessions or cultivars (Table 1) using a Power Plant Pro DNA Isolation kit (MO Bio). Concentration was determined on all samples using a spectrophotometer (NanoDrop 2000c; Thermo Fisher Scientific, Waltham, MA) and template quality was determined for a random subset of samples using a $1 \%$ agarose gel. Each primer was initially tested using DNA from the cultivar The Blues at $50{ }^{\circ} \mathrm{C}$. Gradient polymerase chain reaction (PCR) $\left(45\right.$ to $\left.60{ }^{\circ} \mathrm{C}\right)$ was used for those SSR markers that did not amplify well at $50{ }^{\circ} \mathrm{C}$. For the diversity study, DNA samples were aliquoted into strip tubes to form an array and the sample 'The Blues' was included twice on the array to ensure PCR amplification reliability. Each SSR marker was amplified from each template using a $10-\mu \mathrm{L}$ reaction volume that contained $2 \mu \mathrm{L}$ of $5 \times$ Clear GoTaq reaction buffer (Promega, Madison, WI), $1 \mu \mathrm{L}$ of $25 \mathrm{~mm}$ $\mathrm{MgCl}_{2}, 0.8 \mu \mathrm{L}$ of $2.5 \mathrm{~mm}$ dNTP mix, $0.5 \mu \mathrm{L}$ of M13-tagged forward primer, $2.0 \mu \mathrm{L}$ of reverse primer at $1 \mu \mathrm{M}, 1.8 \mu \mathrm{L}$ of $1 \mu \mathrm{M}$ M13 primer (M13-TGTAAAACGACGGCCAGT) fluorescently labeled with the IRDye $800 \mathrm{CW}$ fluorophore (Eurofins MWG Operon, Huntsville, AL), $0.04 \mu \mathrm{L}$ of GoTaq DNA polymerase (Promega), $0.86 \mu \mathrm{L}$ of sterile water, and $1 \mu \mathrm{L}$ of $2.5 \mathrm{ng} \cdot \mu \mathrm{L}^{-1}$ DNA. Thermocycler conditions were: an initial denaturation at $94{ }^{\circ} \mathrm{C}$ for $3 \mathrm{~min}, 39$ cycles of $94{ }^{\circ} \mathrm{C}$ for $30 \mathrm{~s}, 45$ to $60{ }^{\circ} \mathrm{C}$ (Supplemental Table 1 ) for $1 \mathrm{~min}, 72^{\circ} \mathrm{C}$ for $1 \mathrm{~min} 10 \mathrm{~s}$, and a final elongation step at $72{ }^{\circ} \mathrm{C}$ for $10 \mathrm{~min}$. The thermocycler used was a Gene Amp PCR System 9700 dual block (Applied Biosystems, Foster City, CA). The individual PCR products $(2 \mu \mathrm{L})$ were combined with $5 \mu \mathrm{L}$ of Blue Stop 
Table 1. Schizachyrium accessions and cultivars that were examined for ploidy level and genetic variation.

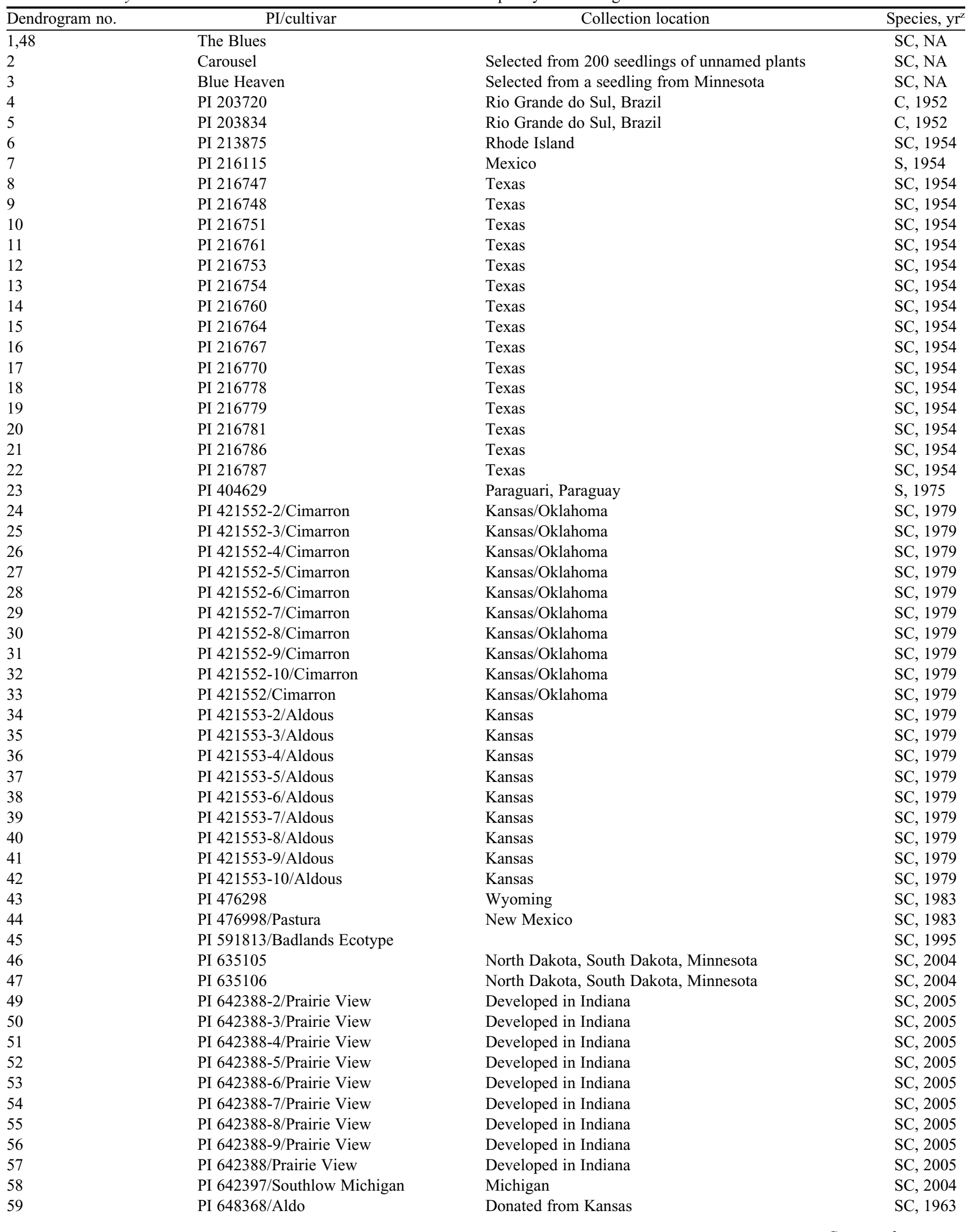


Table 1. Continued.

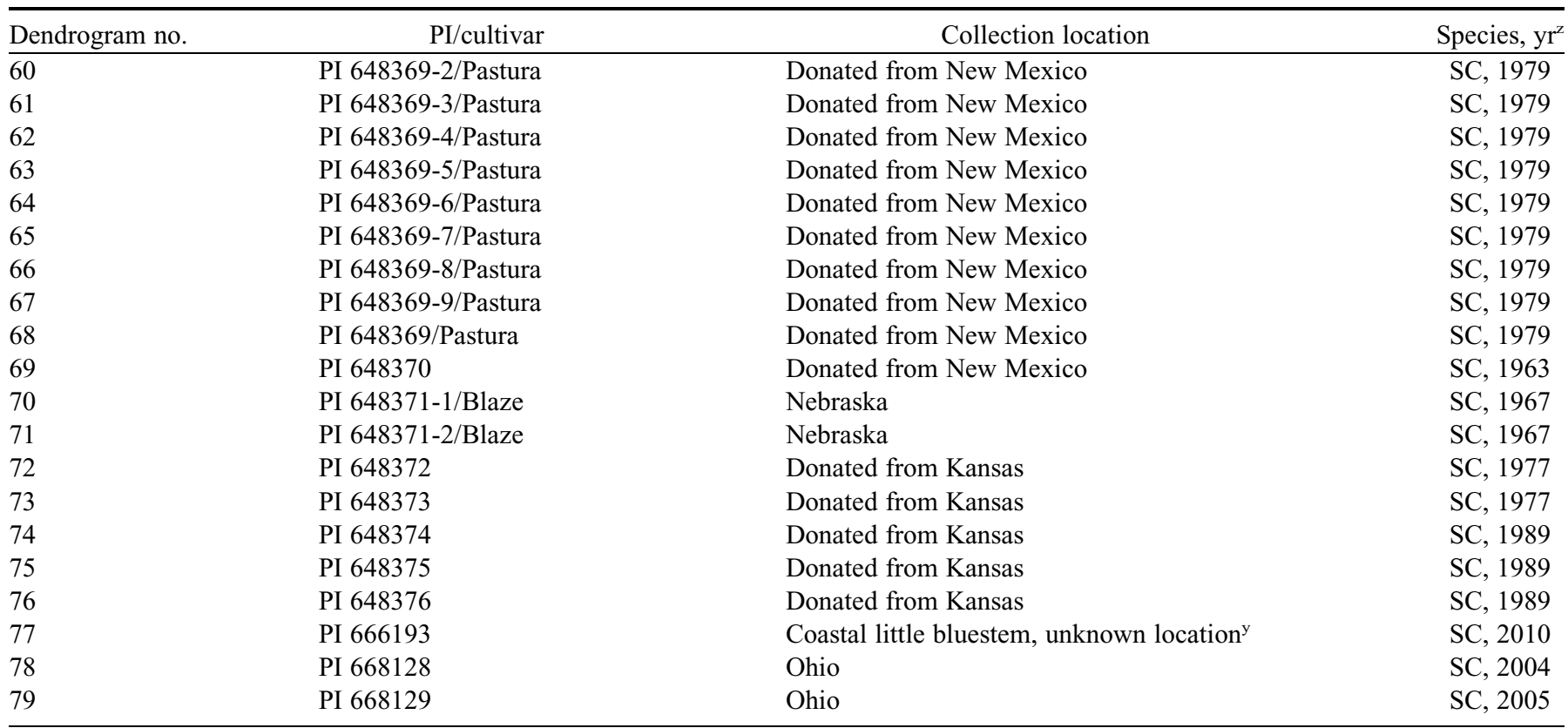

${ }^{\mathrm{z}}$ Schizachyrium species: $\mathrm{C}=$ condensatum, $\mathrm{S}=$ sanguineum, $\mathrm{SC}=$ scoparium $;$ Year $=$ year donated to the USDA-ARS National Plant Germplasm System; NA = cultivar is not an accession in the USDA-ARS National Plant Germplasm System.

${ }^{y} S$. scoparium var. littoralis.

(LI-COR Biosciences, Lincoln, NE) and $0.35 \mu \mathrm{L}$ of this mixture was loaded on a $6.5 \% \mathrm{v} / \mathrm{v}$ acrylamide gel using a 4300 DNA Analyzer (LI-COR Biosciences). Gel images were scored visually and coded as a " 1 " for presence of a band or " 0 " for absence of a band for each accession for each marker. The polymorphism information content (PIC) value and expected heterozygosity were calculated using an online PIC calculator (University of Liverpool, 2002).

Generation of SSR MARKers From Genbank SEQUenCES. The National Center for Biotechnology (NCBI) nucleotide database was searched using the keywords "Schizachyrium," "Andropogon," and "Hyparrhenia" and 52, 67, and 40 nucleotide sequences were identified, respectively. Using the program SSRIT (Temnykh et al., 2001), 21, 17, and 11 sequences contained SSR repeats with a motif a pentameter in length or less with at least four repeats in Schizachyrium, Andropogon, and Hyparrhenia sequences. Assembly of these 49 sequences using Sequencher 4.10.1 (Gene Codes Corp., Ann Arbor, MI) generated eight singletons and 10 contigs. A single sequence was selected from eight contigs and eight singletons and primers were designed using Primer3 (Rozen and Skaletsky, 2002) to amplify the repeat.

Cloning of PCR amplicons. Amplicons from three primer pairs (developed from the ion torrent sequencing), 148812, 149427, and 15116, that generated more than four fragments per accession were selected for sequencing. PCR reactions contained $12.4 \mu \mathrm{L}$ of water, $4 \mu \mathrm{L}$ of $5 \times$ Phusion HF buffer, $0.4 \mu \mathrm{L}$ of $10 \mathrm{~mm}$ dNTPs, $1 \mu \mathrm{L}$ of $10 \mu \mathrm{M}$ forward primer, $1 \mu \mathrm{L}$ of $10 \mu \mathrm{M}$ reverse primer, $0.2 \mu \mathrm{L}$ of DNA polymerase (Phusion; Thermo Fisher Scientific), and $1 \mu \mathrm{L}$ of $100 \mathrm{ng} \cdot \mu \mathrm{L}^{-1}$ 'The Blues' DNA. PCR reactions were carried out in a thermocycler (PTC100; MJ Research, Waltham, MA). After $30 \mathrm{~s}$ of denaturation at $98{ }^{\circ} \mathrm{C}, 30$ cycles were performed with $10 \mathrm{~s}$ at $98{ }^{\circ} \mathrm{C}, 30 \mathrm{~s}$ at $50{ }^{\circ} \mathrm{C}, 1 \mathrm{~min}$ at $72{ }^{\circ} \mathrm{C}$, and a final extension step of $10 \mathrm{~min}$ at $72{ }^{\circ} \mathrm{C}$. One microliter of unpurified PCR products was ligated into pJET1.2/blunt Cloning Vector following the manufacturer's instructions (Thermo Fisher Scientific). The ligation mixture was used to transform chemically competent Escherichia coli, Turbocells (Genlantis, San Diego, CA). Transformed E. coli cells were plated onto Luria Broth plate supplemented with $100 \mu \mathrm{g} \cdot \mathrm{mL}^{-1}$ of ampicillin. To confirm the presence of an insert in the resulting transformants, colony PCR was carried out using the pJET1.2 forward and reverse sequencing primers. Plasmids, containing inserts, were isolated from overnight E. coli cultures grown in Luria Broth with $100 \mu \mathrm{g} \cdot \mathrm{mL}^{-1}$ of ampicillin using a PureYield Plasmid Miniprep System (Promega). Seven independent clones generated with each primer pair were sequenced by Eurofins Genomics (Huntsville, AL).

Cluster analysis. For the unweighted pair group method with arithmetic mean (UPGMA) cluster analysis, marker data were imported into NTSYSpc (Rohlf, 2008). Genetic similarity between each pair of accessions was calculated using the SIMQUAL module using the DICE coefficient of similarity (Nei and Li, 1979). A dendrogram was generated from the similarity matrix by using the UPGMA procedure in the SAHN module of NTSYSpc. The software program FreeTree (Hampl et al., 2001) was used to do the bootstrapping analysis and the number of repetitions was 1000 . Only bootstrap values greater than $50 \%$ are shown (Figs. 1 and 2). For the Bayesian cluster analysis, groupings were analyzed using Structure software Version 2.3 (Pritchard et al., 2000) using a burn-in period of 10,000 and 50,000 Markov Chain Monte Carlo replications for all Schizachyrium samples and a burn-in period of 50,000 and 50,000 Markov Chain Monte Carlo replications for $S$. scoparium samples. The parameters were set to an admixture model with allele frequencies correlated. To determine the best $\mathrm{K}$ (number of populations), the $\mathrm{L}(\mathrm{K})$ procedure (Pritchard et al., 2000) was used by performing a batch job from $\mathrm{K}=1$ to $\mathrm{K}=10$ and the delta $\mathrm{K}$ procedure (Evanno et al., 2005) was used by performing a batch job from $\mathrm{K}=1$ to $\mathrm{K}=10$ with 


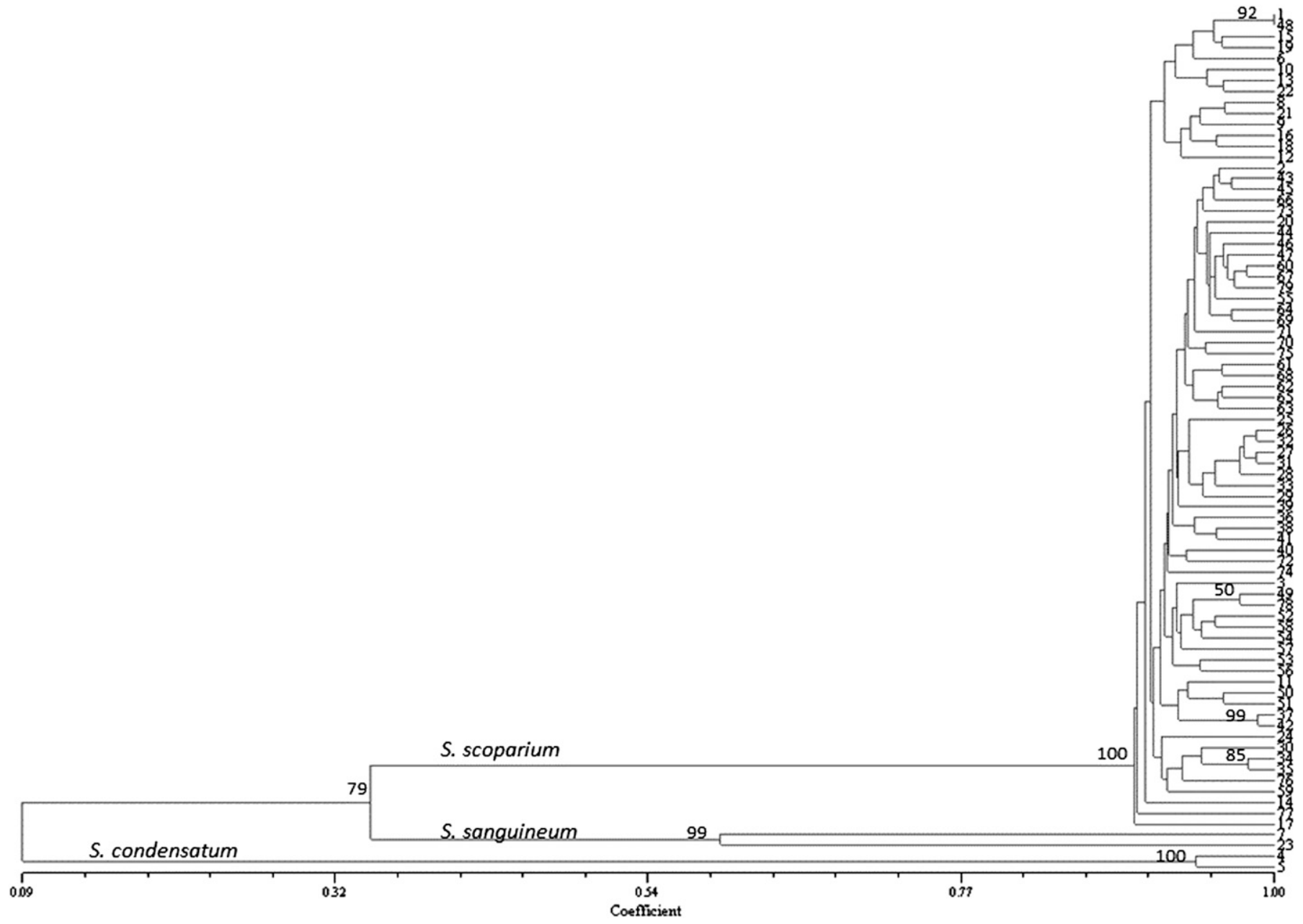

Fig. 1. Unweighted pair group method with arithmetic mean cluster analysis for all Schizachyrium samples.

20 iterations for all Schizachyrium samples and 11 iterations for the $S$. scoparium samples. The program Structure Harvester was used to calculate $\Delta \mathrm{K}$ (Earl and vonHoldt, 2012).

Flow CytOMETRY. Schizachyrium samples were processed for analysis on a BD Accuri C6 flow cytometer (Becton Dickinson, Franklin Lakes, NJ) by first adding $1 \mathrm{~mL}$ of Tris$\mathrm{MgCl}_{2}$ nuclei extraction buffer (Pfosser et al., 1995) to 0.02 to $0.03 \mathrm{~g}$ of fresh leaf tissue using a modified protocol (Galbraith, 2009). An assumed tetraploid sample $(2 n=4 x=40)$, accession PI 213875, was cochopped with each sample. Tissue was chopped using an Astra double-edged razor blade (Procter \& Gamble Hungary, Budapest, Hungary) until fully macerated. The resulting slurry was then pipetted into a $50-\mu \mathrm{m}$ CellTrics disposable filter (Partec, Munster, Germany) sitting on top of a plastic $12 \times 75-\mathrm{mm}$ culture tube. The filter was removed and $500 \mu \mathrm{L}$ of Rnase/propidium iodide solution (BD Biosciences, San Jose, CA) was added to each filtered sample. Samples were then placed on ice for $15 \mathrm{~min}$ and then analyzed on the flow cytometer by gating the selected objects that exhibited a strong correlation between the FL2 and FL3 signals. At least 50,000 events were collected for each sample, the flow rate was set to custom $(11 \mu \mathrm{L}$ sample per minute), and the mean FL2 was recorded for the Gap 1 (G1) and G2 peaks. The flow cytometry procedure was repeated for samples producing wide peaks, where the $\mathrm{CV}$ of the mean FL2 data was greater than $5 \%$ or if samples showed a different ploidy than $4 \times$. Variation in ploidy level was determined based on the G1, G2 sample peaks relative to the control G1, G2 peaks.

\section{Results and Discussion}

GeNOME SEQuencing. Ion torrent PGM sequencing of 'The Blues' with a 318 chip generated a total of $681.37 \mathrm{Mb}$ data and $2,654,634$ quality reads in a single run. Sequences were deposited into the NCBI database under the BioProject accession PRJNA265209. The length of the reads ranged from 50 to 450 bp with an average of $256 \mathrm{bp}$. All reads were assembled into 8713 contigs with a mean length of $2063 \mathrm{bp}$. A total of 2813 SSRs was identified from the contigs and $32.3 \%$ of the contigs contained SSRs. Sequences were considered to contain SSRs if they contained a motif 2 to 6 bp in length and the SSR length was at least $12 \mathrm{bp}$. The most frequent types of SSR were trinucleotide motifs followed by tetranucleotide motifs (Table 2).

Of the 8713 contigs developed, the first 337 contigs were examined to determine the frequency of repetitive elements. The majority of sequences [297 of 337 (88\%)] had homology to repetitive elements. Long terminal repeat (LTR) retrotransposons, DNA transposons, non-LTR retrotransposons, retroviruses, and integrated viruses were identified. The most common repetitive elements were Gypsy LTR retrotransposons 


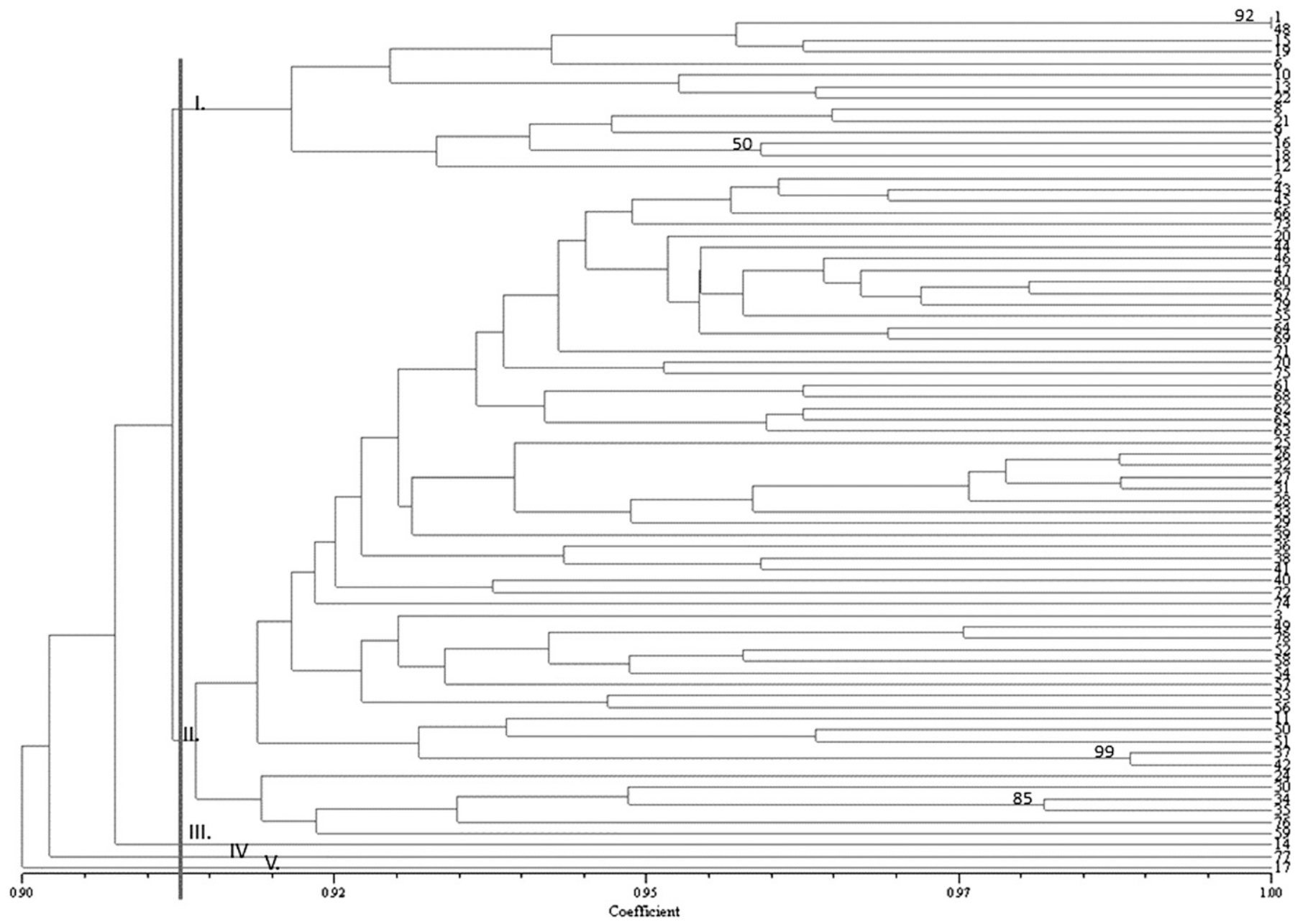

Fig. 2. Unweighted pair group method with arithmetic mean cluster analysis for Schizachyrium scoparium samples.

Table 2. Summary of perfect microsatellite motif classes identified in contigs from ion torrent personal genome machine sequencing of a genomic DNA library of Schizachyrium scoparium 'The Blues'.

\begin{tabular}{|c|c|c|c|c|c|}
\hline & \multicolumn{5}{|c|}{ Class of repeat } \\
\hline & Dinucleotide & Trinucleotide & Tetranucleotide & Pentanucleotide & Hexanucleotide \\
\hline Loci identified (no.) & $458(16.3 \%)$ & $1267(45.1 \%)$ & $716(25.5 \%)$ & $220(7.8 \%)$ & $151(5.4 \%)$ \\
\hline Range of repeats (no.) & 6-22 & 4-24 & 3-7 & 3-6 & 3-8 \\
\hline
\end{tabular}

(338 elements), EnSpm/CACTA DNA transposons (119 elements), and Copia LTR retrotransposons (104 elements). The sequencing of grass genomes has revealed that the transposable element content in these genomes can be quite high, especially as the size of the genome increases [rice (Oryza sativa, 35\% transposable elements), sorghum (Sorghum bicolor, 62\%), maize (Zea mays, 85\%) (Hua-Van et al., 2011)]. Low coverage sequencing using 454 technology in Aegilops cylindrica and A. geniculata [wild relatives of wheat (Triticum aestivum)] identified that more than $70 \%$ of the reads obtained were transposable elements, primarily LTR retrotransposons (Senerchia et al., 2013). Little bluestem has a genome size of $\approx 4303.2 \mathrm{Mbp}$ (assuming $1 \mathrm{pg}=978 \mathrm{Mbp}$ ) (Bai et al., 2012), which is larger than maize at $2900 \mathrm{Mbp}$ (Hua-Van et al., 2011) but smaller than wheat at 15,000 Mbp (Paterson et al., 2005). Its genome, from our low-coverage sequencing, appears rich with repetitive elements.
USE OF EXISTING RESOURCES. There are currently 52 nucleotide sequences available in GenBank (Benson et al., 2005) for the genus Schizachyrium generated from phylogeny studies of the tribe Andropogoneae (Mathews et al., 2002; Teerawatananon et al., 2011). Of these 52 sequences, 21 contain SSR repeats and assembly of these sequences generated one contig and nine singletons. To increase the number of SSR markers from multiple loci, all of the nucleotide sequences from GenBank of the related genera Andropogon (67) and Hyparrhenia (40) (Mathews et al., 2002) were downloaded, screened for SSRs, and those sequences containing SSRs were assembled forming 10 contigs and eight singletons. Primers were developed from the contig and singleton sequences and 11 were of sufficient quality to be scored for all the Schizachyrium accessions (Supplemental Table 1; these sequences are represented by two letters followed by six numbers, e.g., JQ951654). Five of the 11 
SSR markers from GenBank sequences were polymorphic among $S$. scoparium accessions.

AMplification OF SCHIZACHYRIUM ACCESSIONS. The number of SSR primer sets designed was 2812 (Supplemental Table 1). For many plant species, a higher degree of polymorphism has been seen in Class I microsatellites (20 bp or greater) than in Class II microsatellites (12 to 19 bp) (Pandey et al., 2013; Temnykh et al., 2001). Thus, 95 SSR primer pairs and five SSR primer pairs were selected with a repeat length of $20 \mathrm{bp}$ or greater (Class I) or 18 bp (Class 2), respectively (Supplemental Table 1). Amplification of these primers with DNA from 'The Blues' (to determine annealing temperature) and from the Schizachyrium collection revealed that 82 primer pairs were of sufficient quality to be scored. The SSR markers that were scored (82 obtained from ion torrent sequencing and 10 from Genbank) contained 24 dimer repeats, 36 trimer repeats, three tetramer repeats, nine pentamer repeats, and 20 hexamer repeats (Supplemental Table 1). The number of scored fragments per primer pair ranged from 0 (monomorphic, single product of the same size) to 12 , which was surprisingly low for a primarily outcrossing tetraploid species and 183 fragments were scored. The average number of scored fragments was 1.98. Furthermore, only 35 primer pairs generated polymorphism of sufficient quality (clear distinct fragments) to be scored among $S$. scoparium accessions (Supplemental Table 1). These 35 primer pairs generated 102 scored fragments. Class I microsatellites [26 polymorphic/78 that amplified (33\%)] were less polymorphic than Class II microsatellites [six of six $(100 \%)$ ] for the S. scoparium accessions, although the number of Class II microsatellites used was small. Twenty-two primer pairs generated more than four fragments per accession and eight of these generated more than 10 fragments per accession. The generation of so many fragments, many at a high annealing temperature, indicates the primers are specifically amplifying multiple regions of the genome.

Three of the primer pairs $(149427,151116$, and 148812) that generated more than four fragments per little bluestem accession were selected and fragments were amplified using 'The Blues' template. Seven clones from each primer pair were sequenced and assembled forming four contigs and two singletons. One sequence from each contig and each singleton sequence was used to search for repetitive elements using the software Censor (Kohany et al., 2006). Primer pair 148812 generated approximately six fragments per accession and all seven clones had no similarity to repetitive elements and formed a single contig. Primer pairs 149427 and 151116 generated more than 10 fragments per little bluestem accession and clones from both primer pairs generated three contigs (two of the three contigs contained sequences from both primer pairs) and two singletons. Four of the five sequences from these two primer pairs had similarity $(79 \%$ to $88 \%$ ) to an En/Spmtype DNA transposon from sorghum.

EXAMINATION OF ALL LITTLE BLUESTEM SSR SEQUENCES FOR REPETITIVE ELEMENTS. Of the 117 sequences containing SSRs that were used to design primers, only nine (8\%) did not have similarity to DNA transposons, retrotransposons, viruses, or satellite sequences when analyzed with Censor software. The most frequent fragments identified were the LTR retrotransposons Gypsy (177 fragments) and Copia (98 fragments) and the DNA transposon EnSpm (60 fragments). Most sequences contained homology to more than one superfamily of repetitive elements (67 of 117). The association between SSR repeats and transposons has been documented in many studies including plants. In rice, an association between (AT)n repeats and the Micropon family of MITEs exists (Temnykh et al., 2001). The authors noted that primers designed to amplify these repeats often generated multiple fragments. In barley (Hordeum vulgare), dinucleotide SSR repeats are associated with retrotransposons and other repetitive elements (Ramsay et al., 1999). In wheat, many of the SSR clones had similarities to LTR retrotransposons causing irregular amplification profiles such as smear products (Koike et al., 2006). In pea (Pisum sativum), variable SSR repeats were identified within the LTR of a pea Ty1/copia retrotransposon and the LTR retrotransposons were shown to contribute to the origin and distribution of microsatellite repeats (Smykal et al., 2009). Thus, the little bluestem sequences that contained SSR repeats, that we examined, are rich with repetitive elements $(92 \%)$ and are much higher than those of previous reports in plants, which found between $24 \%$ and $54 \%$ of the microsatellites to be associated with other repetitive elements (Ramsay et al., 1999; Temnykh et al., 2001; Tero et al., 2006).

Genetic Relationships AMONG SCHIZACHYRIUM SAMPLES. Cluster analysis, using Structure and NTSYS, of the SSR data for all the Schizachyrium samples revealed two major groups. The $S$. condensatum samples formed one group (Wright's measure of population subdivision, Fst $=0.7543$ ) and the $S$. sanguimeum and $S$. scoparium samples formed another group $(\mathrm{Fst}=0.5816)$, although there is clear separation between samples of $S$. sanguineum and $S$. scoparium (Fig. 1). Admixture was measured as 0.0250 , which is close to zero, suggesting that individuals are from one population or another and no interbreeding is occurring (Evanno et al., 2005). Cluster analysis using the UPGMA procedure for the SSR data for only the $S$. scoparium samples revealed five groups but these groups were not strongly supported (bootstrapping less than 50\%) (Fig. 2). Group I consisted of 13 accessions (the sample 'The Blues' was repeated twice to confirm scoring accuracy) primarily collected from Texas, Group II consisted of 58 accessions including all of the individual samples of the forage and conservation cultivars as well as the clonal samples 'Carousel' and 'Blue Heaven'. Samples within this group were collected primarily from locations with latitudes between 34 and $43^{\circ} \mathrm{N}$. Group III and $\mathrm{V}$ consisted each of a sample, PI216760 and PI216770, respectively, collected in 1953 by the Agricultural Experiment Station, College Station, TX. Group IV consisted of a single sample PI 666193, a coastal little bluestem (S. scoparium var. littoralis), of an unknown collection location. Coastal little bluestem grows on the coastal strip from southern New England to Texas and can be distinguished from inland little bluestem by its bent stems at the base of the plant (USDA, 2014).

Because the $S$. scoparium groupings were not well supported using the UPGMA procedure, cluster analysis of the S. scoparium SSR data was performed using the software program Structure Version 2.3, which uses a Bayesian algorithm. Four clusters using the $\Delta \mathrm{K}$ method (Evanno et al., 2005) were identified. Structure Group 2 corresponded to Group I of the UPGMA grouping but with an additional member \#14, which formed Group III in the UPGMA grouping (Fig. 3). The remaining three Structure groups correspond to the UPGMA Group II and the merging of the UPGMA groups with one member to these groups. UPGMA Groups III and V that merged with the larger groups in the Structure clustering were not assigned to these Structure groups at a high probability 

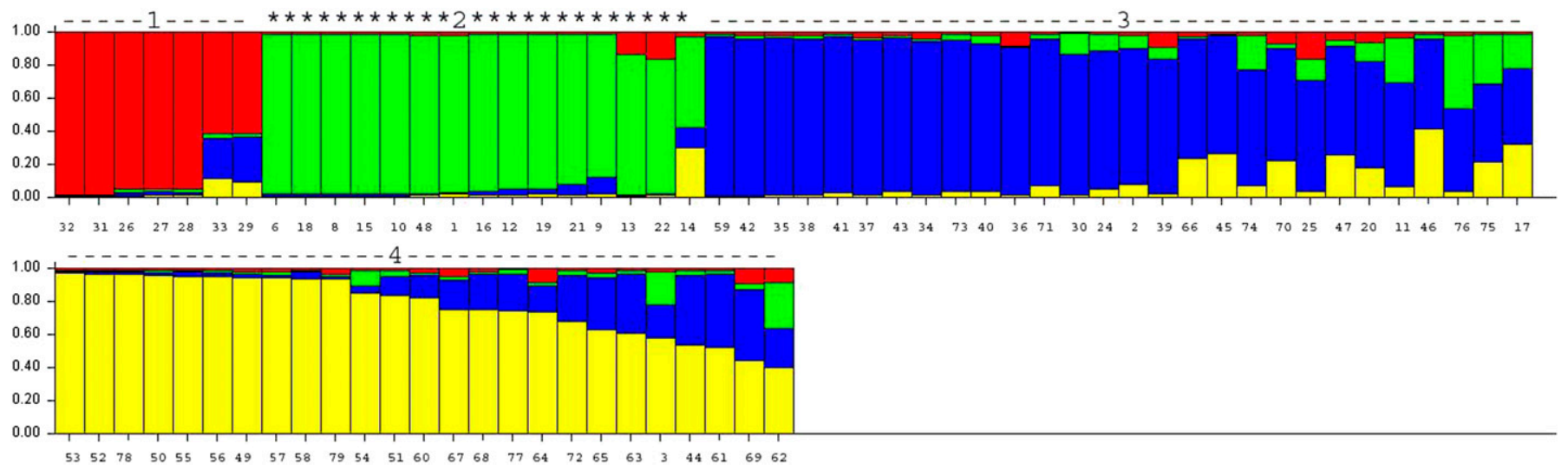

Fig. 3. Bayesian cluster analysis using all Schizachyrium scoparium samples.

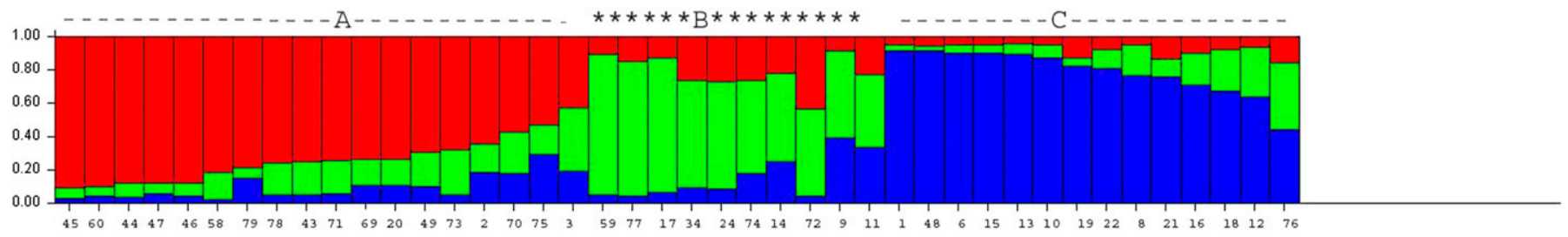

Fig. 4. Bayesian cluster analysis using one plant per accession for all Schizachyrium scoparium samples.

(membership coefficient $=0.56$ and 0.46 , respectively). Structure Group 1 consisted of only the 'Cimarron' accessions. Structure Group 3 corresponded to all the 'Aldous' accessions, the 'Blaze' accessions, three 'Cimarron' accessions, 'Carousel', and accessions from Kansas, Texas, and Wyoming. Structure Group 4 consisted of the 'Prairie View' and 'Pastura' accessions as well as 'Blue Heaven' and accessions from Ohio and New Mexico. Admixture was measured as 0.0577 indicating that little interbreeding between groups is occurring.

Unequal sampling sizes can affect phylogenetic analysis (Nelson and Anderson, 2013). To determine if having an unequal number of individuals (four accessions had nine or 10 plants per accession, whereas the rest had only one plant per accession) affected the number of clusters, only one plant per accession was analyzed for the $S$. scoparium samples. Structure analysis revealed three groups. As to be expected, the group that consisted only of the 'Cimarron' accessions was no longer present in the new analysis. Structure Group A (Fig. 4) consisted of the cultivars Badlands, Pastura, Prairie View, Blaze, Carousel, Southlow Michigan, and Blue Heaven as well as accessions from Kansas, Ohio, Wyoming, Texas, and New Mexico. Structure Group B (Fig. 4) consisted of the cultivars Cimarron and Aldous, accessions from Kansas and Texas, and the coastal little bluestem accession. Structure Group C (Fig. 4) consisted of the samples that belonged to Group I of the UPGMA analysis. These samples included the cultivar The Blues and samples predominantly from Texas.

Future breeding for little bluestem should be done across these cluster groups to determine if they could serve as heterotic groups. Gabriel (2005) found that crossing sorghum lines within groups (groups were defined with molecular markers using UPGMA clustering) exhibited inferior heterotic expression for grain yield and other traits as compared with across group crosses. Similar results were found in tropical maize (Pinto et al., 2003).
Among the S. scoparium accessions, the lowest genetic similarity between accessions was $86 \%$ (Fig. 2). This high level of genetic similarity was a surprise given the high degree of morphological variation seen in this species and previous observations of genetic variation within populations (Fu et al., 2004; Huff et al., 1998). Previous research suggests that genetic diversity correlating with geographic traits among populations is minor compared with the genetic variation within populations (Fu et al., 2004). The high genetic similarity values among accessions could indicate a narrow genetic base. However, the SSR markers that we designed were from sequences that were rich with repetitive elements and may have increased the genetic similarity values, yet for those nine sequences in which the Censor software did not detect other repetitive elements, only seven amplified and three of seven (42\%) markers were polymorphic among $S$. scoparium accessions. This rate of polymorphism is not much higher than for those sequences containing other repetitive elements and that were polymorphic among $S$. scoparium accessions, 32 of 86 (37\%). Furthermore, examination of genetic diversity in natural little bluestem populations in Manitoba and Saskatchewan found the maximum interpopulation distance was $0.13(87 \%$ similar) (Fu et al., 2004). Huff et al. (1998) observed a low level of variation among four little bluestem populations (5\%) in comparison with other outcrossing species. Thus, the low level of interpopulation differentiation may be caused by a high level of genetic variability (Gonzalez-Hernandez et al., 2009), which is inconsistent with our SSR results.

Ecoclinal variation for traits such as maturity, height, leafiness, and disease resistance exists in little bluestem (Anderson and Aldous, 1938; Cornelius, 1947). Phan and Smith (2000) identified differences among ecotypes for culms per plant and seedheads per culm in 3-year-old spaced plants of collected little bluestem from Manitoba. Boe and Bortnem (2009) found 
strong phenotypic plasticity for biomass production and that genetic variation for phenotypic plasticity exists in the cultivar Camper. Furthermore, Springer (2012) used 19 of the little bluestem accessions this study genotyped and found variation for morphological traits such as canopy morphology, height and width of canopy, and leafiness of the culm. Thus, the maximum genetic distance of $14 \%$ found between $S$. scoparium accessions using SSR markers and phenotypic plasticity allows a wide range of morphological phenotypes.

Within-CUltivar VARIABILITY. Examination of withinaccession variability of four forage cultivars, Cimarron, Aldous, Prairie View, and Pastura, showed that all plants from these accessions clustered in UPGMA Group II (Fig. 2), but Structure analysis provided better separation (Fig. 3). From the Structure analysis, accessions from the cultivar Aldous clustered in Group 3 and accessions from the cultivars Prairie View and Pastura clustered in Group 4. Furthermore, from the Structure analysis, seven of the accessions from cultivar Cimarron clustered in Group 1 and three of Cimarron accessions clustered in Group 3 (Fig. 3). This suggests that greater diversity exists within the cultivar Cimarron than within the cultivars Aldous, Prairie View, and Pastura.

Ploidy Variation. Ploidy variation within Schizachyrium has been seen from $2 n=2 x=20$ to $2 n=10 x=100$ (Peichoto et al., 2011). Schizachyrium scoparium has been found to be $2 n=4 x=40$ (Carman and Hatch, 1982); S. condensatum has been found to be $2 n=2 x=20$ and $2 n=4 x=40$ (Peichoto et al., 2011); and $S$. sanguineum has been found to be $2 n=2 x=20$, $2 n=3 x=30,2 n=4 x=40,2 n=5 x=50,2 n=6 x=60,2 n=7 x=$ $70,2 n=8 x=80$, and $2 n=10 x=100$ (Peichoto et al., 2011). Ploidy variation was determined by flow cytometry on the $75 \mathrm{~S}$. scoparium accessions obtained from the USDA and all plants had a ploidy level the same as the assumed tetraploid $(2 n=4 x=40)$. Two accessions each of $S$. condensatum and $S$. sanguimeum were used as outgroups. The accessions of S. condensatum had the diploid cytotype (PI 203720, PI 203834), whereas $S$. sanguimeum had a tetraploid (PI 404629) and octoploid (PI 216115) cytotype (assuming our internal control was a tetraploid).

In summary, the USDA-ARS $S$. scoparium collection was evaluated for ploidy and genetic variation. The next-generation sequencing data for little bluestem is the first data set generated for this important horticultural grass species. Most of the sequences, from which microsatellites were developed, contained other repetitive elements. A set of 35 microsatellite markers was identified that was able to differentiate the $S$. scoparium accessions. UPGMA and Bayesian cluster analysis was used to analyze data from 102 fragments generated from the USDA-ARS $S$. scoparium collection to identify five and four groups, respectively. These microsatellite markers are the first sequence-specific markers designed for little bluestem and can serve as a resource for cultivar identification, pedigree analysis, breeding, etc. The 92 markers developed in this study may be useful in other Schizachyrium species as well.

\section{Literature Cited}

Anderson, K.L. and A.E. Aldous. 1938. Improvement of Andropogon scoparius Michx. by breeding and selection. J. Amer. Soc. Agron. 30:862-869.

Anderson, R.C., A.E. Liberta, and L.A. Diekman. 1984. Interaction of vascular plants and vesicular-arbuscular mycorrhizal fungi across a soil moisture-nutrient gradient. Oecologia 64:111-117.
Bai, C., W.S. Alverson, A. Follansbee, and D.M. Waller. 2012. New reports of nuclear DNA content for 407 vascular plant taxa from the United States. Ann. Bot. (Lond.) 110:1623-1629.

Benson, D.A., I. Karsch-Mizrachi, D.J. Lipman, J. Ostell, and D.L. Wheeler. 2005. GenBank. Nucleic Acids Res. 33:D34-D38.

Boe, A. and R. Bortnem. 2009. Morphology and genetics of biomass in little bluestem. Crop Sci. 49:411-418.

Carman, J.G. and S.L. Hatch. 1982. Aposporous apomixes in Schizachyrium (Poaceae: Andropogoneae). Crop Sci. 22:1252-1255.

Cornelius, D.R. 1947. The effect of source of little bluestem grass seed on growth, adaptation, and use in revegetation seeding. J. Agr. Res. 74:133-143.

Deward, G.W. and S.M. Jalal. 1974. Meiotic behavior and fertility interrelationship in Andropogon scoparius and A. gerardi. Cytologia (Tokyo) 39:215-223.

Earl, D.A. and B.M. vonHoldt. 2012. Structure Harvester: A website and program for visualizing Structure output and implementing the Evanno method. Conservation Genet. Resources 4:359-361.

Egan, A.N., J. Schlueter, and D.M. Spooner. 2012. Applications of next-generation sequencing in plant biology. Amer. J. Bot. 99:175185.

Evanno, G., S. Regnaut, and J. Goudet. 2005. Detecting the number of clusters of individuals using the software STRUCTURE: A simulation study. Mol. Ecol. 14:2611-2620.

Fernald, M.L. 1950. Gray's manual of botany. 8th ed. American Book Company, New York, NY.

Fu, Y., A.T. Phan, B. Coulman, and K.W. Richards. 2004. Genetic diversity in natural populations and corresponding seed collections of little bluestem as revealed by AFLP markers. Crop Sci. 44:22542260.

Gabriel, K. 2005. A study of heterotic relationships in sorghum. $\mathrm{PhD}$ diss., Texas A\&M Univ., College Station, TX.

Galbraith, D. 2009. Simultaneous flow cytometric quantification of plant nuclear DNA contents over the full range of described angiosperm 2C values. Cytometry 75A:692-698.

Gonzalez-Hernandez, J.L., G. Sarath, J.M. Stein, V. Owens, K. Gedye, and A. Boe. 2009. A multiple species approach to biomass production from native herbaceous perennial feedstocks. In Vitro Cell. Dev. Biol. Plant 45:267-281.

Hampl, V., A. Pavlícek, and J. Flegr. 2001. Construction and bootstrap analysis of DNA fingerprinting-based phylogenetic trees with a freeware program FreeTree: Application to trichomonad parasites. Intl. J. Syst. Evol. Microbiol. 51:731-735.

Hamrick, J.L. and M.J.W. Godt. 1989. Allozyme diversity in plant species, p. 43-62. In: Brown, A.H.D., M.T. Clegg, A.L. Kahler, and B.S. Weir (eds.). Plant population genetics, breeding and genetic resources. Sinauer, Sunderland, MA.

Harris-Shultz, K., P. Raymer, B.E. Scheffler, and R.S. Arias. 2013. Development and characterization of seashore paspalum SSR markers. Crop Sci. 53:1-7.

Hua-Van, A., A. Le Rouzic, T.S. Boutin, J. Filee, and P. Capy. 2011. The struggle for life of the genome's selfish architects. Biol. Direct $6: 19$.

Huff, D.R., J.A. Quinn, B. Higgins, and A.J. Palazzo. 1998. Random amplified polymorphic DNA (RAPD) variation among native little bluestem [Schizachyrium scoparium (Michx.) Nash] populations from sites of high and low fertility in forest and grassland biomes. Mol. Ecol. 7:1591-1597.

Kohany, O., A.J.L. Hankus, and J. Jurka. 2006. Annotation, submission and screening of repetitive elements in Repbase: RepbaseSubmitter and Censor. BMC Bioinformatics 7:474.

Koike, M., K. Kawaura, Y. Ogihaara, and A. Torada. 2006. Isolation and characterization of SSR sequences from the genome and TAC clones of common wheat using the PCR technique. Genome 49:432444.

Mathews, S., R.E. Spangler, R.J. Mason-Gamer, and E.A. Kellogg. 2002. Phylogeny of andropogoneae inferred from phytochrome B, GBSSI, and NDHF. Intl. J. Plant Sci. 163:441-450. 
Meyer, M.H. 2012. Ornamental grass in the USA. Hort. Rev. 39:121-152. Mulkey, S.E., M.C. Zuleta, J.E. Keebler, J.E. Schaff, and S.R. MillaLewis. 2013. Development and characterization of simple sequence repeat markers for st. augustinegrass. Crop Sci. 54:401-412.

Nei, M. and W.H. Li. 1979. Mathematical model for studying genetic variation in terms of restriction endonucleases. Proc. Natl. Acad. Sci. USA 76:5269-5273.

Nelson, M.F. and N.O. Anderson. 2013. How many marker loci are necessary? Analysis of dominant marker data sets using two popular population genetic algorithms. Ecol. Evol. 3:3455-3470.

Pandey, G., G. Misra, K. Kumari, S. Gupta, S.K. Parida, D. Chattopadhyay, and M. Prasad. 2013. Genome-wide development and use of microsatellite markers for large-scale genotyping applications in foxtail millet [Setaria italic (L.)]. DNA Res. 20:197-207.

Paterson, A.H., M. Freeling, and T. Sasaki. 2005. Grains of knowledge: Genomics of model cereals. Genome Res. 15:1643-1650.

Peichoto, M.C., F. Galdeano, M.M. Arbo, and V.G. Solis Neffa. 2011. Chromosome number and ploidy level of some South American species of Schizachyrium (Poaceae, Andopogoneae). Plant Syst. Evol. 292:63-71.

Pfosser, M., A. Amon, T. Lelley, and E. Heberle-Bors. 1995. Evaluation of sensitivity of flow cytometry in detecting aneuploidy in wheat using disomic and ditelosomic wheat-rye addition lines. Cytometry 21:387-393.

Phan, A.T. and S.R. Smith, Jr. 2000. Seed yield variation in blue grama and little bluestem plant collections in southern Manitoba Canada. Crop Sci. 40:555-561.

Pinto, R., D.I. de Souza, L.A. Carlini-Garcia, A.A.F. Garcia, and A. Pereira de Souza. 2003. Comparison between molecular markers and diallel crosses in the assignment of maize lines to heterotic groups. Maydica 48:63-73.

Pritchard, J.K., M. Stephans, and P. Donnelly. 2000. Inference of population structure using multilocus genotype data. Genetics 155:945-959.

Ramsay, L., M. Macaulay, L. Cardle, M. Morgante, S. Degli Ivanissevich, E. Maestri, W. Powell, and R. Waugh. 1999. Intimate association of microsatellite repeats with retrotransposons and other dispersed repetitive elements in barley. Plant J. 17:415-425.

Rohlf, F.J. 2008. NTSYSpc: Numerical taxonomy system. Version 2.20. Exeter Publ., Setauket, NY.

Rozen, S. and H.J. Skaletsky. 2002. Primer3. 31 Oct. 2014. <http:// www-genome.wi.mit.edu/genome_software/other/primer3.html>.

Senerchia, N., T. Wicker, F. Felber, and C. Parisod. 2013. Evolutionary dynamics of retrotransposons assessed by high-throughput sequencing in wild relatives of wheat. Genome Biol. Evol. 5:10101020.

Smith, S.R., Jr. and R.D.B. Whalley. 2002. A model for expanded use of native grasses. Native Plants J. 3:38-49.

Smykal, P., R. Kalendar, R. Ford, J. Macas, and M. Griga. 2009. Evolutionary conserved lineage of Angela-family retrotransposons as a genome-wide microsatellite repeat dispersal agent. Heredity 103:157-167.

Springer, T.L. 2012. Variation for canopy morphology in little bluestem. Crop Sci. 52:729-737.

Teerawatananon, A., S.W.L. Jacobs, and T. Hodkinson. 2011. Phylogenetics of Panicoideae (Poaceae) based on chloroplast and nuclear DNA sequences. Telopea (Syd.) 13:115-142.

Temnykh, S., G. DeClerck, A. Lukashova, L. Lipovich, S. Cartinhour, and S. McCouch. 2001. Computational and experimental analysis of microsatellites in rice (Oryza sativa L.): Frequency, length variation, transposon association, and genetic marker potential. Genome Res. 11:1441-1452.

Tero, N., H. Neumeier, R. Gudavalli, and C. Schlotterer. 2006. Silene tatarica microsatellites are frequently located in repetitive DNA. J. Evol. Biol. 19:1612-1619.

Toth, G., Z. Gaspari, and J. Jurka. 2000. Microsatellites in different eukaryotic genomes. Survey and analysis. Genome R 10:967-981.

University of Liverpool. 2002. PIC calculator. 3 Sept. 2014. <http:// www.liv.ac.uk/ kempsj/pic.html>.

U.S. Department of Agriculture. 2012. Census of agriculture-2009. Census of horticultural specialties. 3 Sept. 2014. $<$ http:// www.agcensus.usda.gov/Publications/2007/Online_Highlights/ Census_of_Horticulture_Specialties/index.php $>$.

U.S. Department of Agriculture. 2013. National Genetic Resources Program. Germplasm Resources Information Network (GRIN). 3 Sept. 2014. <http://www.ars-grin.gov>.

U.S. Department of Agriculture. 2014. Plant fact sheet - Coastal little bluestem. 3 Sept. 2014. <http://plants.usda.gov/factsheet/pdf/ fs_scli11.pdf $>$.

Wuenscher, M.L. and G.C. Gerloff. 1971. Growth of Andropogon scoparius (little bluestem) in phosphorus deficient soils. New Phytol. 70:1035-1042.

You, F.M., N. Huo, Y.Q. Gu, M. Luo, Y. Ma, D. Hane, G.R. Lazo, J. Dvorak, and O.D. Anderson. 2008. BatchPrimer3: A high throughput web application for PCR and sequencing primer design. BMC Bioinformatics 9:253. 